\title{
Tinjauan Struktur Pada Pembangunan Hotel Aimas Convention Center Kabupaten Sorong
}

\author{
NURWIAH BUGIS \\ Jurusan Teknik Sipil, Fakultas Teknik , Universitas Muhammadiyah Sorong
}

\begin{abstract}
Abstrak
Dalam pembangunan suatu Gedung perlu suatu perencanaan yang matang di tinjau dari segi keamanan, ekonomi, kegunaan , arsitektur Gedung Hotel Aimas Convention Center terdiri dari 4 Lantai, Struktur gedung ini merupakan Struktur Beton Bertulang . dan dalam tugas akhir ini akan di rencanakan Struktur Gedung Beton Bertulang menggunakan Sistem Rangka Pemikul Momen Khusus (SRPMK) sesuai dengan Peraturan terbaru yaitu SNI 28742013 (Persyaratan beton struktural untuk bangunan gedung dan SNI 17262012 ( Tata cara perencanaan ketahanan gempa untuk struktur bangunan gedung dan non gedung). Tahapan perencanaan struktur diantaranya menganalisa keadaan serta kondisi tanah, perancangan konfigurasi struktur bangunan berikut sistem strukturnya, penentuan beban-beban yang bekerja pada struktur, penentuan dimensi dan penulangan elemen struktur, dan terakhir pembuatan gambar disain.Perhitungan beban gempa dilakukan berdasarkan wilayah gempa yang menjadi dasar untuk menentukan Sistem Rangka Pemikul Momennya. Perencanaan ini bertujuan agar apabila terjadi gempa kuat, sendi plastis dapat terbentuk pada elemen struktur balok. Guna menjamin terjadinya sendi plastis pada balok tersebut, maka kolom harus di desain lebih kuat dari balok (Strong column weak beam ). Pada struktur bawah di gun akan pondasi Pile cap , karena tanah pada area pembangunan gedung termasuk jenis tanah lunak. Dari hasil perhitungan yang telah di lakukan menggunakan bantuan program SAP2000 menunjukan bahwa elemen struktur gedung Hotel ini aman secara analisa dengan pembebanan gempa.
\end{abstract}

Kata Kunci : Struktur Beton Bertulang dan Sistem Rangka Pemikul Khusus .

\section{PENDAHULUAN}

Proyek pembangunan hotel aimas convention center merupakan salah satu sarana untuk memenuhi kebutuhan masyarakat dan dapat di gunakan untuk berbagai macam kepentingan sesuai kapsitas bangunannya.

Dalam pelaksanaan sebuah bangunan gedung hendaknya seorang perencana mampu memberikan gambaran tentang bentuk dan ukuran dari bangunan gedung yang direncanakan, di dalam penentuan-penentuan tersebut seorang perencana dapat dibantu dengan memanfaatkan teknologi yang sudah ada sesuai perkembangan ilmu pengetahuan saat ini.

Bangunan hotel aimas convention center tidak terlepas dari perencanaan struktur gedung serta pembebanan yang perlu diperhatikan. Struktur bangunan terdiri atas dua bagian yakni struktur atas dan struktur bawah . struktur atas suatu gedung adalah seluruh bagian struktur yang berada di atas muka tanah. Struktur bawah adalah seluruh bagian struktur yang berada di bawah permukaan tanah yang termasuk dalam struktur suatu gedung adalah pondasi.

Pembangunan suatu gedung harus di tinjau beban-beban yang meliputi beban hidup, beban mati dan beban akibat gempa. Perhitungan pembebanan dilakukan untuk mengetahui batas yang di butuhkan oleh struktur bangunan agar bangunan hotel aimas convention center tidak mengalami kegagalan struktur Kekuatan strukur sangat bergantung pada jenis sistem struktur yang di pilih. Adapun tujuan penelitian ini adalah untuk mengetahi hasil dari tinjaun struktur atas (pelat,balok,kolom) dan struktur bawah (pondasi).

\section{METODOLOGI}

Pelaksanaaan penelitian ini dimulai dari bulan Agustus hingga bulan Oktober 2017. Untuk membuat perencanaan struktur pembangunan gedung di perlukan data sebagai bahan acuaan. Data tersebut dapat di klasifikasikan kedalam dua jenis data yaitu (1)Data Primer, data yang di peroleh sendiri dari lokasi proyek pembangunan dan yang ke (2) Data Sekunder, data yang di peroleh dari perusahaan ataupun data yang diminta langsung ke perusahaan.

Garis besar pada langkah-langkah perencanaan struktur gedung disajikan dalam bentuk flowchart pada gambar 1 .

\section{HASIL DAN PEMBAHASAN}

3.1 Pemodelan Struktur Secara 3D

Pemodelan Struktur secara 3 dimensi dapat diihat Gambar 2.

3.2 Konfigurasi Gedung

Fungsi Gedung

: Hotel

Lebar dalam arah $\mathrm{x}$

: $46.4 \mathrm{~m}$

Lebar dalam arah y

: $16 \quad \mathrm{~m}$

Jumlah Lantai

Tinggi Bangunan
: 4 + Atap

$: 12.7 \mathrm{~m}$ 


\section{JURNAL RANCANG BANGUN Vol 2 (2)45-51 2017}

Tinggi tiap Lantai

Lantai 1-2

$\begin{array}{lll}\text { Lantai 2-3 } & : 3.2 & \mathrm{~m} \\ \text { Lantai 3-4 } & : 3.2 & \mathrm{~m} \\ \text { Lantai 4 - ke Atap } & : 3.1 & \mathrm{~m}\end{array}$

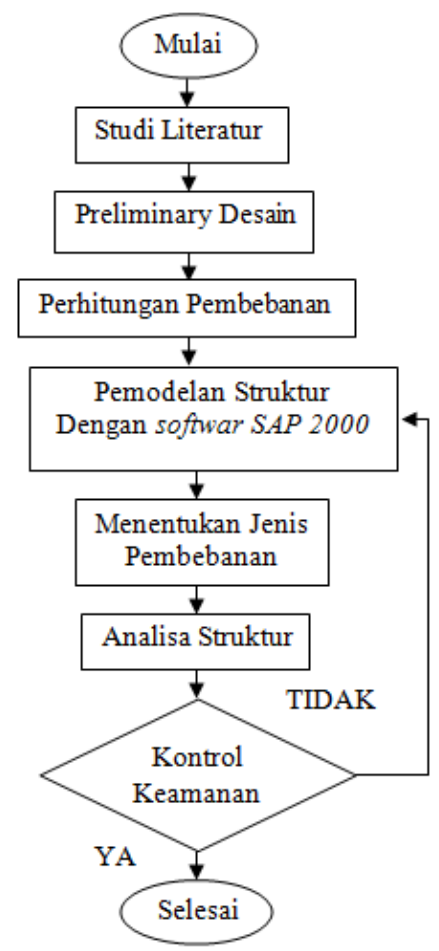

Gambar1. Flow Chart Perencanaan Struktur

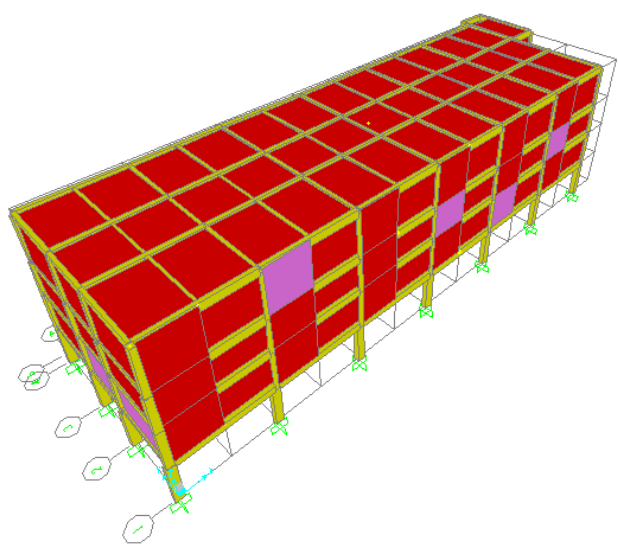

Gambar2. Pemodelan Struktur 3 Dimensi

\subsection{Perhitungan Pembebanan}

Beban mati (DL)

Beban sendiri pelat $0,13 \mathrm{~cm}$ x $2400 \mathrm{Kg} / \mathrm{m}^{3}$ $: 312 \mathrm{Kg} / \mathrm{m}^{2}$

Plafond + Penggantung $\quad: 13,3 \mathrm{Kg} / \mathrm{m}^{2}$
Mekanika \& Elektrikal $\quad: 25 \mathrm{Kg} / \mathrm{m}^{2}$

Spesi $\left(0,03 \mathrm{~m} \mathrm{x} 2100 \mathrm{Kg} / \mathrm{m}^{3}\right): 63 \mathrm{Kg} / \mathrm{m}^{3}$

Tegel $\left(0,01 \mathrm{~m} \times 2400 \mathrm{Kg} / \mathrm{m}^{3}\right) \quad 24 \mathrm{Kg} / \mathrm{m}^{2}$

Dinding $1 / 2$ batu $\quad: 250 \mathrm{Kg} / \mathrm{m}^{2}$

Beban Hidup (LL)

Beban hidup untuk lantai ruang : $195,79 \mathrm{Kg} / \mathrm{m}^{2}$

Beban Angin (WL) $\quad: 40 \mathrm{Kg} / \mathrm{m}^{2}$

Beban Air Hujan $\quad: 30 \mathrm{Kg} / \mathrm{m}^{2}$

\subsection{Menghitung Berat Total Gedung}

Beban Atap

Beban Mati

Penutup Atap $: 432 \times 2400 \quad: 1036800 \mathrm{Kg}$

Plafond $\quad: 432 \times 6,3 \quad: 2721,6 \mathrm{Kg}$

M\&E $\quad: 432 \times 25: 10800 \mathrm{Kg}$

Balok ( 20/30) : 65 x 0,2 x 0,3 x 2400: $9360 \mathrm{Kg}$

Beban Hidup

Beban untuk atap: 432x97,8927: 42289,6464 Kg

Beban air hujan : $432 \times 30 \quad: 12960 \mathrm{Kg}$

$$
\mathrm{Wt}=\sum \mathrm{DL}+\sum \mathrm{LL}
$$

$: 1050532,416+16574,89392 \quad: 1067107,31 \mathrm{Kg}$

\section{Beban Lantai 4}

Beban Mati

Pelat lantai: 431 x $0.13 \times 2400 \quad: 134472 \mathrm{Kg}$

Plafond $\quad: 431 \times 6.3 \quad: 2715,3 \mathrm{Kg}$

M\&E $\quad: 431 \times 25 \quad: 10775 \mathrm{Kg}$

Spesi + Tegel $: 431 \times 87 \quad: 37497 \mathrm{Kg}$

Balok (20/30) : (65 x 0,20 x 0,30 x 2400)

: $9360 \mathrm{Kg}$

Kolom ( 40/40) : $(0,40 \times 0,40 \times 28 \times 3,2 \times 2400)$

Perabotan $\quad: 431 \times 150 \quad: 64650 \mathrm{Kg}$

Dinding $1 / 2$ batu : $358.952 \times 3.2 \times 250$

Beban Hidup

: 287161,6 Kg

Beban Lantai : $431 \times 195,79 \quad: 84385,49 \mathrm{Kg}$ $\mathrm{Wt}=\sum \mathrm{DL}+\sum \mathrm{LL}$

$571888,116+25315,647$

: 597203,763 Kg

Tabel 1. Total berat gedung (Wt)

\begin{tabular}{|c|c|c|c|}
\hline Lantai & $\mathrm{W}_{\mathrm{D}}(\mathrm{Kg})$ & $\mathrm{W}_{\mathrm{L}}(\mathrm{Kg})$ & $\mathrm{Wi}(\mathrm{Kg})$ \\
\hline Atap & 1050532,416 & 16574,89392 & 1067107,31 \\
\hline 4 & 571888,116 & 25315,647 & 597203,763 \\
\hline 3 & 931638,9 & 25315,647 & 956954,547 \\
\hline 2 & 503962,1 & 25315,647 & 529277,747 \\
\hline 1 & 589512,948 & 25315,647 & 614828,595 \\
\hline \multicolumn{3}{|c|}{ Berat total (Wt) } & 3765371,962 \\
\hline
\end{tabular}




\section{JURNAL RANCANG BANGUN Vol 2 (2)45-51 2017}

\subsection{Menentukan Kategori Risiko Bangunan}

Menentukan faktor kategori resiko angunan berdasarkan SNI 1726:2012 tentang tata cara perencanaan ketahanan empa untuk struktur bangunan gedung dan non gedung . gedung ini termasuk dalam kategori risiko II. semua kategori risiko struktur bangunan gedung dan non gedung rencana terhadapnya harus di kalikan dengan suatu faktor keutamaan Ie . gedung hotel aimas center di rencanakan sebagai bangunan apartemen bangunan ini termasuk kategori II sehingga di dapat nilai Ie $=1,0$ dalam proses desain seismik kita harus menghitung parameter percepatan desain seismik (Sds dan $\mathrm{Sd}_{1}$ ).Penentuan parameter percepatan gempa dapat dilakukan dengan mengakses web desain speksta Indonesia yang di sediakan pada Kementrian Pekerjaaan Umum. Dari hasil output dari situs dessain spectra Indonesia adalah sebagai berikut :

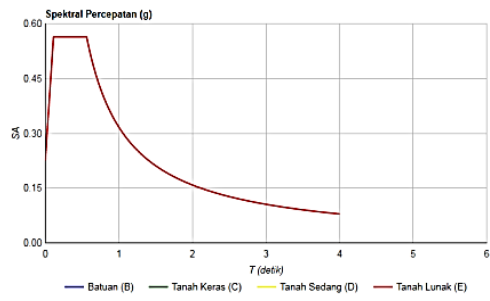

Gambar3. Tampilan nilai spekral percepatan di permukaan, hasil output nilai E dalam kondisi tanah lunak.

Dari hasil output desain spectra indonesia diperoleh nilai $\mathrm{Sds}=0.564$ dan nilai $\mathrm{S}_{\mathrm{D} 1}=$ 0.317. Berdasarkan tabel 6 SNI 1726:2012 tentang kategori desain sesmik pada parameter respon percepatan perode pendek $\left(\mathrm{S}_{\mathrm{DS}}\right)$ diperoleh pada kategori risiko $\mathrm{D}$. dan menurut tabel 7 SNI 1726:2012 tentang kategori desain sesmik pada parameter respon percepatan pada periode 1 detik $\left(S_{D 1}\right)$ diperoleh kategori risiko $D$. Oleh karena itu dalam perencanaan gedung Hotel aimas convention center kabupaten Sorong digunakan sistem rangka pemikul Momen Khusus (SPRMK). gedung ini menggunakan material beton pracetak biasa berdasarkan SNI 1726:2012 didapatkan nilai faktor pembesaran defleksi $(C d)=3$ nilai koefisien modifikasi respon $(\mathrm{R})=8$ dan nilai factor kuat lebih sistem $(\Omega x)=51 / 2$.

\subsection{Perhitungan Tulangan Pelat}

Data Perencanaan

$$
\begin{array}{ll}
L_{x} & =3,6 \mathrm{~m} \\
L_{y} & =5 \mathrm{~m} \\
\text { F'c } & =30 \mathrm{Mpa} \\
\text { Fy } & =400 \mathrm{Mpa} \\
\beta I & =0.83(\text { SNI } 2847: 2013 \text { Pasal 10.2.7.3) } \\
\mathrm{b} & =1000 \mathrm{~mm} \\
\mathrm{~h} & =120 \mathrm{~mm}
\end{array}
$$

Selimut beton /decking $(\mathrm{p})=20 \mathrm{~mm}$

(SNI 2847:2013 Pasal 7.7)

$\emptyset$ tul. Lentur $=19 \mathrm{~mm}$

$d_{x}=120-20-(10 / 2)=95 \mathrm{~mm}$

\begin{tabular}{|c|c|c|}
\hline $\begin{array}{l}\text { Tipe } \\
\text { Pelat }\end{array}$ & $\mathrm{Mu}(\mathrm{Nm}$ & $\begin{array}{l}\text { Dimensi } \\
\text { Tulangan }\end{array}$ \\
\hline \multirow[t]{4}{*}{ Atap } & Tumpuan x : 282606 & D10-200mm $\mathrm{m}^{2}$ \\
\hline & Lapangan x : 12117 & D10-200mm ${ }^{2}$ \\
\hline & Tumpuan y : 484469 & D10-200mm ${ }^{2}$ \\
\hline & Lapangan y : 370080 & D10-200mm ${ }^{2}$ \\
\hline \multirow[t]{4}{*}{ Lantai } & Tumpuan x : 344603 & D10-200mm ${ }^{2}$ \\
\hline & Lapangan x : 147687 & D10-200mm ${ }^{2}$ \\
\hline & Tumpuan y : 590748 & D10-200mm ${ }^{2}$ \\
\hline & Lapangan y: 452266 & D10-200mm $\mathrm{m}^{2}$ \\
\hline
\end{tabular}

$d_{y}=120-20-10-(10 / 2)=85 \mathrm{~mm}$

Asumsi jenis pelat : jepit elastic $\frac{L_{y}}{L_{x}}=\frac{5}{3,6}=1,38$ sehingga termasuk kedalam pelat 2 arah (SNI 2847:2013 pasal 9.5.3)

$$
\begin{aligned}
M_{\text {Tum }} \mathrm{x} & =-0.001 \times q_{u} \times L_{x}{ }^{2} \mathrm{x} \\
M_{\text {Lap }} \mathrm{x} & =0.001 \times q_{u} \times L_{x}{ }^{2} \times \mathrm{X} \\
m & =\frac{f_{y}}{0.85 \times f^{\prime} c} \\
\rho_{\text {min }} & =\frac{0.25 \sqrt{ } f c}{f y} \\
\rho b & =\frac{0.85 \times \beta 1 \times f^{\prime} c}{f y}\left(\frac{600}{600+f y}\right) \\
\rho b & =0.0317 \\
\rho_{\max } & =0.75 \times \rho b \\
\rho_{\max } & =0.75 \times 0.0317=0.0238
\end{aligned}
$$

Tabel 2. Rekapitulasi Perhitungan Pelat 


\section{JURNAL RANCANG BANGUN Vol 2 (2)45-51 2017}

\subsection{Perhitungan Tulangan Balok}

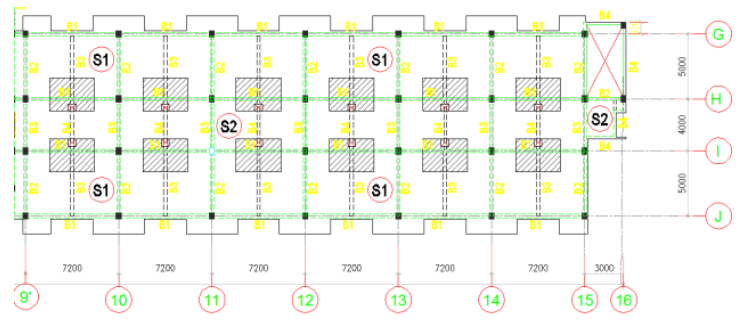

Gambar4. Denah Balok

Data Perencanaa Bentang balok : $7200 \mathrm{~mm}$

Dimensi balok (b ) : $300 \mathrm{~mm}$

Dimensi balok (h) : $600 \mathrm{~mm}$

Kuat tekan beton (fc'): $30 \mathrm{Mpa}$

Kuat leleh tulangan lentur (fy): $400 \mathrm{Mpa}$

Dalam merencanakan tulangan pada balok untuk memudahkan pada proses pengerjaan di lapangan balok di samakan dengan tulangan kolom yaitu D19 dan perlu di ketahui dahulu momen dan gaya yang bekerja pada balok tersebut . berikut perhitungan dan detail penampang balok 300x600mm dengan panjang $7.2 \mathrm{~m}$. Pada balok B300x600mm dengan panjang 7,2 m di ketahui Mu+ yaitu sebear 126533804 $\mathrm{Nmm} \mathrm{Mu-} \mathrm{sebesar} \mathrm{100853133,3} \mathrm{Nmm} \mathrm{dan} \mathrm{gaya}$ geser $\mathrm{Vu}$ sebesar $85277,58 \mathrm{Nmm}$ setelahnya di hitung manual sehingga di dapat tulangan positif 2D22 dan tulangan negative 2D22 dan tulangan geser D10-125 mm.

Cek syarat SPRMK untuk kekuatan lentur pada balok Kekuatan momem positif pada muka joint harus tidak kurang dari setengah kekuatan momen negative yang di sediakan pada muka joint tersebut. Baik kekuatan momen negative atau positif pada penampang sepanjang komponen struktur tidak boleh kurang dari seperempat kekuatan momen maksimum yang di sediakan pada muka salah satu dari joint tersebut ( SNI 2847:2013 pasal 21.5.2.2)
Tabel 3. Rekapitulasi Penulangan Balok
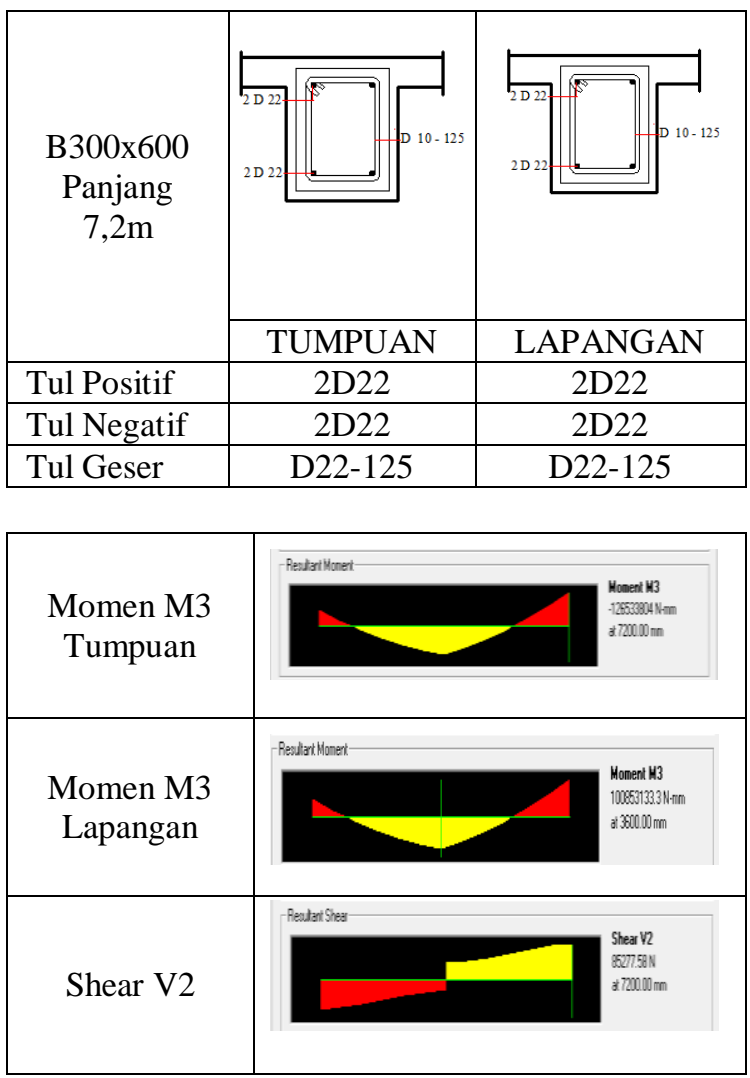

Gambar5. Diagram momen dari SAP2000

\subsection{Perhitungan Perencanaan Kolom}

Kolom yang didesain direncanakan dengan ukuran 400 x $600 \mathrm{~mm}$ dan tinggi 3,2 m.

(1). Syarat Kolom SRPMK berdasarkan SNI 032847-2002 Pasal. 23. (2). balok SRPMK harus memenuhi syarat sebagai berikut : Gaya aksial tekan terfaktor yang bekerja pada kolom melebihi0,1.Ag.f'c- Ukuran penampang terkecil kolom tidak kurang dari $300 \mathrm{~mm}-$ Perbandingan antara ukuran terkecil penampang terhadap ukuran dalamarah tegak- lurusnya tidak kurang dari 0,4 Rasio tulangan harus memenuhi $0,01-<\rho<0,06$. Menurut ketentuan SNI 2847:2013 pasal 21.3.2 perlu diperhitungkan gaya aksial balok untuk menetukan perhitungan detail tulangan balok tulangan balok. Berikut perhitungan syarat aksial balok sebagai berikut :

$\frac{A g \times f^{\prime} c}{10}=\frac{400 \times 600 \times 30}{10}=720000 \mathrm{~N}$ 


\section{JURNAL RANCANG BANGUN Vol 2 (2)45-51 2017}

Berdasarkan analisa struktur SAP 2000 v.14 gaya aksial tekan akibat kombinasi pembebanan 1.2DL + 1LL + 1E pada komponen struktur sebesar $706079,58 \mathrm{~N}>694319,55 \mathrm{~N}$. karena nilai gaya tekan aksial terfaktor $(\mathrm{Pu})$ untuk komponen struktur lebih besar dari pada hasil perhitungan diatas maka detail penulanagan struktur rangka harus memenuhi SNI 2847:2013 pasal 21.3.5

Kontrol kelangsingan kolom

$\beta=\frac{1.2 P u_{D l}}{P u_{1.2 D L+1.6 L L}}=0,0898$

Panjang tekuk kolom $\psi=\frac{\sum\left(\frac{E l}{L}\right)_{\text {kolom }}}{\sum\left(\frac{E I}{L}\right)_{\text {balok }}}$

$\mathrm{EI}=\frac{0.4 \times E c \times I g}{1+\beta_{d}}$ diperoleh nilai factor panajng tekuk kolom (k) sebesar 1.6. Radius girasi girasi boleh diambil 0.3 kali dimensi untuk komponen struktur tekan persegi. Sehingga diperoleh $\rho_{\text {perlu }}$ $=3 \%=0.03$ Perhitungan tulangan kolom As perlu $=\rho_{\text {perlu }} \times \mathrm{b} \times \mathrm{h}$. Perencanaan tulangan geser $S_{\text {maks }}<\frac{d}{2}$ atau $S_{\text {maks }}<600 \mathrm{~mm}$. Dari persyaratan diatas spasi sengkang yang diambil nilai terkecil yaitu $152 \mathrm{~mm}$ dan untuk jarak sengkang pasang tidak boleh melebihi spasi minimum dari persyaratan tersebut. Direncanakan menggunakan tulangan $\varnothing 10-300$ mm dengan 2 kaki, maka luasan tulangan geser adalah

$\mathrm{Av}=\left(0.25 \times \pi \times d^{2}\right) \times 2 k a k i$

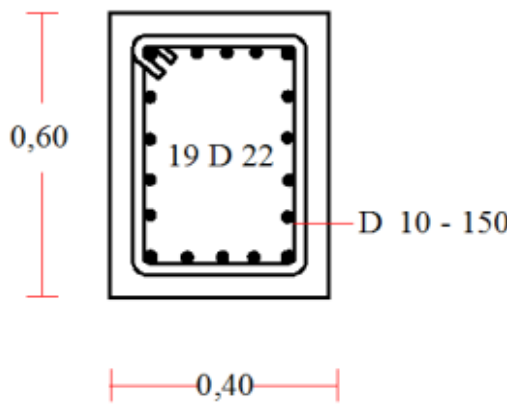

Gambar 6. Detail Penulangan Kolom

Periksa :

$\mathrm{S}_{\text {pasang }}=150 \mathrm{~mm}<\mathrm{S}_{\min }=152 \mathrm{~mm}$ (memenuhi)

$A v_{\text {pasang }}=157 \mathrm{~mm}>A v_{\text {min }}=50,93 \mathrm{~mm}$ (memenuhi)

$A v_{\text {pasang }}=157 \mathrm{~mm}>A v_{\text {min }}=52,5 \mathrm{~mm}$ (memenuhi)

\subsection{Perencanaan Pondasi}

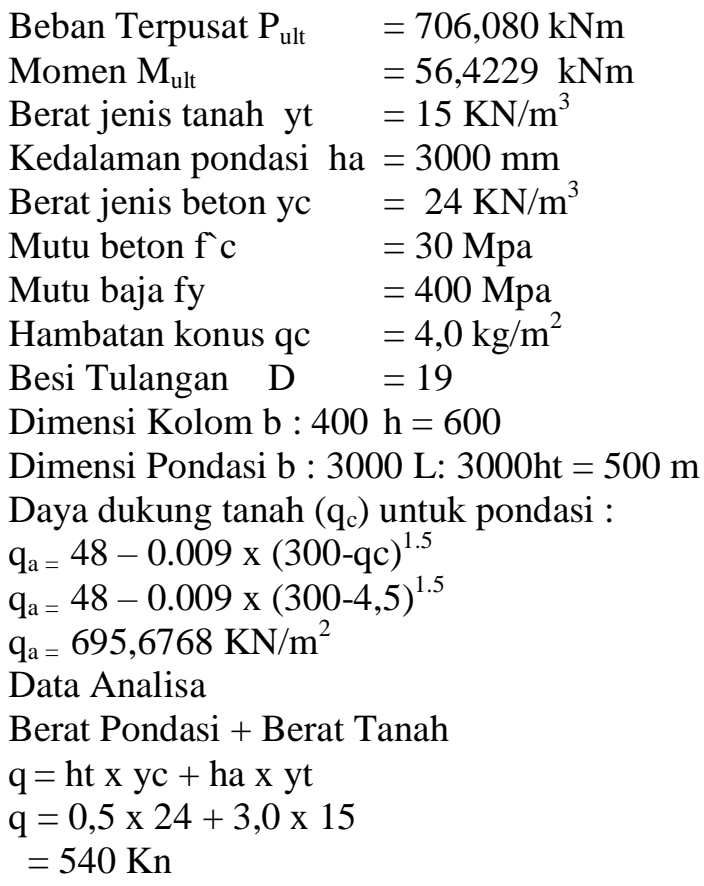

Cek Pondasi terhadap tegangan izin tanah

Tegangan yang terjadi pada tanah

$$
\begin{aligned}
\text { Qmaks } & =\frac{\text { Pult }}{B . L}+\frac{\text { Mult }}{\frac{1}{6} B . L}+\mathrm{q} \\
& =\frac{706,080}{3 \times 3}+\frac{56,4229}{\frac{1}{6} 3 \times 3}+540
\end{aligned}
$$

Qmaks $=656,068 \mathrm{Kn} / \mathrm{m}^{2}$

Qmin $=\frac{\text { Pult }}{B \cdot L}+\frac{\text { Mult }}{\frac{1}{6} B \cdot L}+\mathrm{q}$

$\mathrm{Qmin}=\frac{706,080}{3 \times 3}+\frac{56,4229}{\frac{1}{6} 3 \times 3^{2}}+540$

Qmin $=630,991 \mathrm{kN} / \mathrm{m}^{2}$

Kontrol tegangan geser satu arah

$\mathrm{d}_{\mathrm{s}} \quad=75+\mathrm{d} / 2$

$\mathrm{d}_{\mathrm{s}} \quad=84,5 \mathrm{~mm}$

$\mathrm{d}=\mathrm{h}_{\mathrm{t}}-\mathrm{d}_{\mathrm{s}}$

$\mathrm{d} \quad=500-84,5$

$\mathrm{d} \quad=415,5 \mathrm{~mm}$

a $\quad=\frac{B}{2}-\frac{b}{2}-\mathrm{d}$

a $\quad=\frac{3000}{2}-\frac{400}{2}-415,5$ 


\section{JURNAL RANCANG BANGUN Vol 2 (2)45-51 2017}

$$
\begin{array}{ll}
\mathrm{a} & =884 \mathrm{~mm}=0,884 \mathrm{~m} \\
\sigma \mathrm{a} & =\sigma_{\min }+(\mathrm{B}-\mathrm{a}) \mathrm{x} \frac{q \text { maks-qmin}}{b} \\
\text { бa } & =640,466 \mathrm{kN} / \mathrm{m}^{2}
\end{array}
$$

Gaya tekan ke atas dari tanah $(\mathrm{Vu})$

$\mathrm{Vu}=(\mathrm{B} \times \mathrm{a}) \times\left(\frac{q m a k s+q a}{2}\right)$

$\mathrm{Vu}=339,42 \mathrm{kN} / \mathrm{m}^{2}$

Gaya geser yang di tahan oleh beton

$\varnothing \mathrm{Vc}=\varnothing \frac{\sqrt{f c}}{6} . \mathrm{B} \cdot \mathrm{d}$

$\varnothing \mathrm{Vc}=853 \mathrm{kN} / \mathrm{m}^{2}$

Cek $\varnothing \mathrm{Vc}>\mathrm{Vu}$

$$
=853 \mathrm{kN} / \mathrm{m}^{2}>339,42 \mathrm{kN} / \mathrm{m}^{2} \ldots . \text { (memenuhi) }
$$

Kontrol tegangan geser dua arah

As perlu $=0.0042 \times 3000 \times 415,5=5235 \mathrm{~mm}^{2}$

As $_{\min }=0.0071 \times 3000 \times 415,5=8850 \mathrm{~mm}^{2}$

Dipasang 20 D 19 atau D19 - 225.

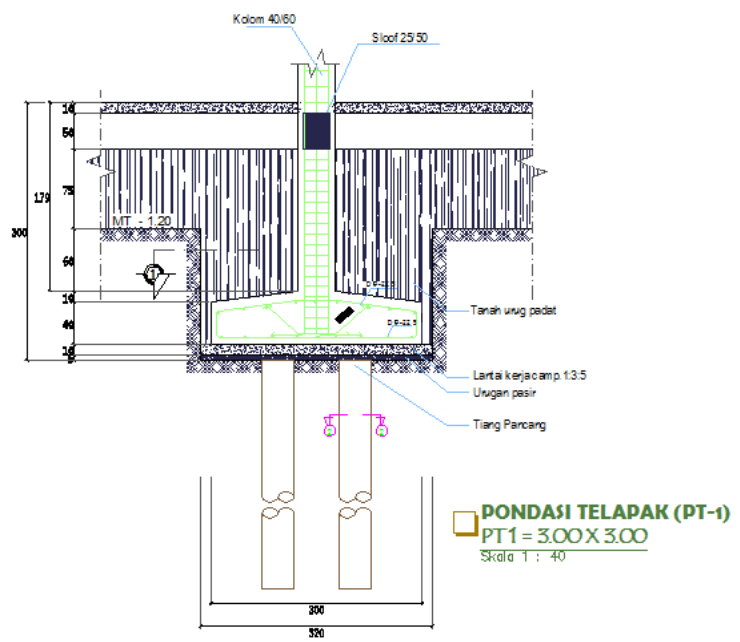

Gambar 7. Detail Penulangan Pondasi

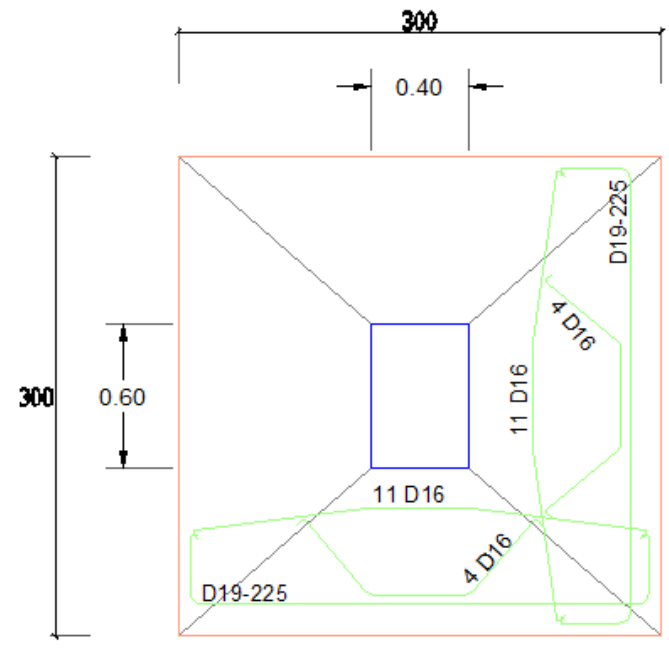

Gambar 8. Potongan Pondasi

\section{KESIMPULAN}

(1) Penentuan tipe struktur pada SNI Gempa 1726-2012 denganperhitungan terlebih dahulu, kemudian dikelompokkan berdasarkan Kategori Desain Seismik (KDS), tipe bangunan termasuk KDS tipe $\mathrm{D}$ atau memiliki tingkat resiko kegempaan kuat sehingga struktur diperhitungkan dengan cara Sistem Struktur Pemikul Momen Khusus (SRPMK). (2) ,Gedung Kuliah didesain berdasarkan konsep strong colomn weak beam dengan tata cara perhitungan Sistem Stuktur Rangka Pemikul Momen Khusus (SRPMK), sehingga gedung diharapkan dapat berprilaku menjadi struktur yang daktail dan memiliki simpangan yang besar apabila gedung menerima beban gempa kuat.

\section{DAFTAR PUSTAKA}

Badan Standar Nasional (2013): Beban minimum untuk Prencanaan Bangunan Gedung dan Struktur lain - SNI 1727

Badan Standar Nasional (2013): Persyaratan Beton Struktural untuk Bangunan Gedung SNI 2874

Badan Standar Nasional (2012): Tata Cara Perencanaan Ketahanan Gempa Untuk Struktur Bangunan Gedung dan non Gedung - SNI 1726.

Gideon, H, Ir (1993). Dasar-Dasar Perencanaan Beton Bertulang Jakarta : Erlangga 


\section{JURNAL RANCANG BANGUN Vol 2 (2)45-51 2017}

Harsipin A. (2017). Tinjauan Struktr Pada Pembangunan Ruko Km12. Sorong UMS

Kaffah Silmi Akbar Farisal (2017). Perhitungan Strukturr Gedung Perkuliahan Universitas Trunojoyo . Surabaya

Setiawan A (2013). Perencanaan Struktur Beton Bertulang Jakarta:Erlanggaa

Wang C,K dan Salmon, C.G (1986). Desain Beton Bertulang Jilid 1 (edisi keempat) Jakarta : Erlangga 